\title{
A rare case of pancreatitis following scoliosis correction
}

\author{
Chinthaka Gayasri Hewavitharane ${ }^{1^{*}}$, Saman Jayathilaka ${ }^{2}$ \\ Senior Registrar in Anaesthesiology $y^{*}$, Consultant Anaesthesiologist ${ }^{2}$, Department of Anaesthesia, \\ National Hospital of Sri Lanka, Sri Lanka.
}

\begin{abstract}
Acute pancreatitis following major spinal surgery is a rare potential complication. Several mechanisms such as positioning, intraoperative haemodynamic instability, mechanical compression and prolonged surgery can contribute to it. This should be suspected in a patient presenting with gastrointestinal symptoms, signs and raised serum amylase or lipase. Our case report is of a young patient with low BMI developing postoperative acute pancreatitis after single stage correction of right thoracic idiopathic scoliosis at National Hospital of Sri Lanka. Early identification of complications plays a key role in preventing severe morbidity after scoliosis surgery. When symptoms and signs are suggestive of abdominal complications, biochemical markers have to be analyzed for prompt diagnosis. Multidisciplinary approach and imaging are further steps in the differential diagnosis and management of this rare complication.
\end{abstract}

Keywords: Pancreatitis; scoliosis; prone position; amylase; low BMI; postoperative complications

\section{Introduction}

Acute pancreatitis following major spinal surgery is a rare complication. This life threatening condition is usually seen related to alcohol, gall stone disease and idiopathic causes. Also, it is caused by iatrogenic causes such as ERCP, pancreatic resections, bowel surgery, splenectomy and cardiac surgery. ${ }^{1-5}$ Although several cases are reported in the medical literature, this is the first documented case in Sri Lanka.

\section{Case presentation}

This young 13-year-old girl had severe proximal thoracic (T3-T6) scoliosis (Figure 1) with deformity (Cobb's angle of $84^{\circ}$ ) and weighed $32 \mathrm{~kg}$ with a BMI of $16.32 \mathrm{~kg} / \mathrm{m}^{2}$.

Routine preoperative assessment showed a restrictive lung function (FEV1/FVC 93\%). The transthoracic echo showed mitral valve

\footnotetext{
*Correspondence: Chinthaka Gayasri Hewavitharane E mail: chinxhewavitharane@gmail.com
}

https://orcid.org/0000-0003-3103-6658

Received: 20/06/2019

Accepted: 08/12/2019

DOI: http:/doi.org/10.4038/slia.v28i1.8476

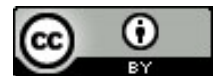

Figure 1: 3D reconstruction of the spine and chest $\mathrm{x}$-ray
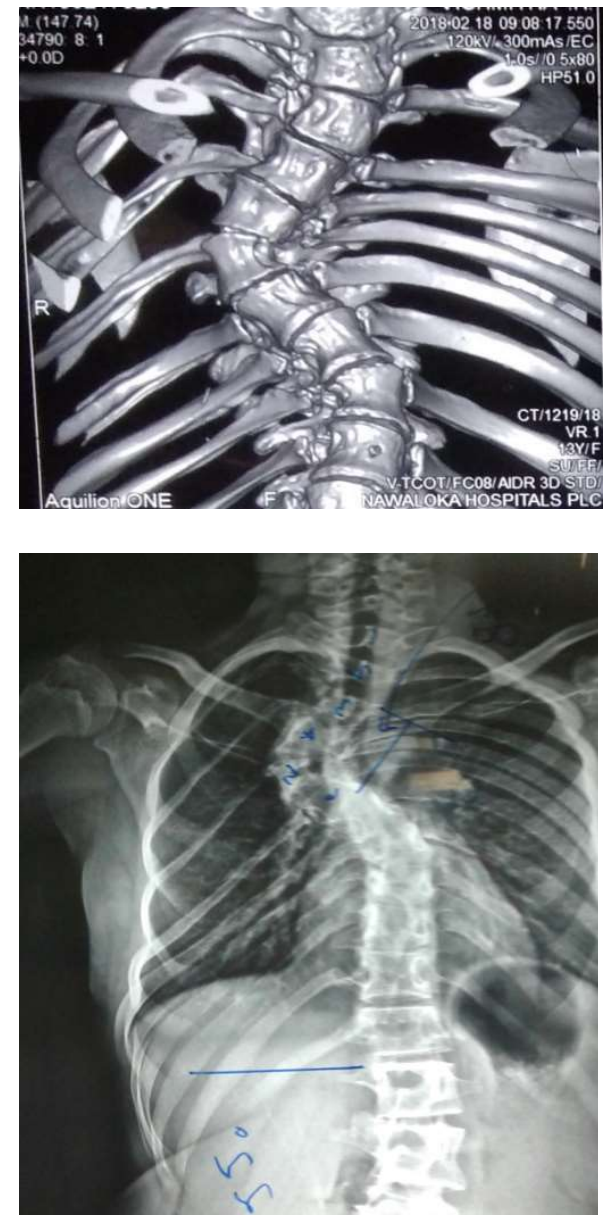
prolapse with mild mitral regurgitation and no pulmonary hypertension. She underwent single stage posterior correction of scoliosis. The surgery was 9 hours long and done in prone position under TIVA with propofol and remifentanil. The blood loss was about a litre and was replaced with $1 \mathrm{~L}$ of blood and $2 \mathrm{~L}$ of crystalloids during the surgery. She had pedicle screws inserted at T1, 2, 3 and T8, 9, 10 levels. Intraoperatively, somatosensory evoked potentials were monitored and the right sided $\mathrm{T} 1$ pedicle screw had to be removed due to loss of signal 1 hour after insertion. Screws were not inserted at T2-3 and T7-9 on the right side due to lack of pedicles on the vertebrae (Figure 2). She was transferred to surgical intensive care unit for postoperative monitoring.

Figure 2: Postoperative chest x-ray

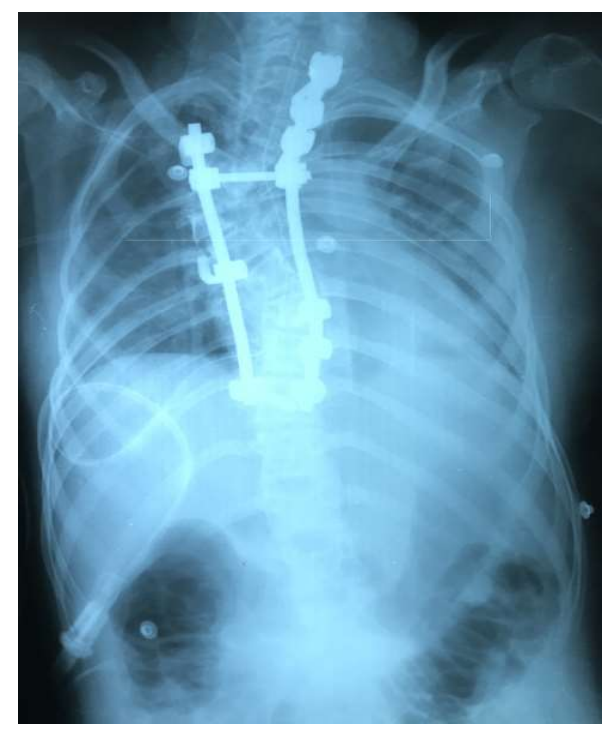

She had stable haemodynamics and respiratory parameters on day 1 and 2. There were no neurological deficits. She was on oral clear fluids initially and later commenced on liquid diet on day 2. Good pain control was achieved with morphine PCA.

On day 3, she developed abdominal pain, mild distension associated with nausea, vomiting and low grade fever. Bowel sounds were diminished. Her acute abdominal pain could have been caused by acute appendicitis, paralytic ileus, superior mesenteric artery syndrome or acute pancreatitis. Laboratory results showed a white cell count of $26 \times 10^{3} / \mu 1, \mathrm{C}$ - reactive protein $173 \mathrm{mg} / \mathrm{L}$ and serum amylase level of 454 IU/L. An ultrasound scan of the abdomen revealed intestinal distention with mild to moderate free fluid. CECT showed swollen pancreatic head and peri-pancreatic fluid confirming the diagnosis of acute pancreatitis (Figure 3). She also had bilateral mild pleural effusions with consolidation of both lung bases.

Figure 3: CECT of the abdomen Pancreatic head

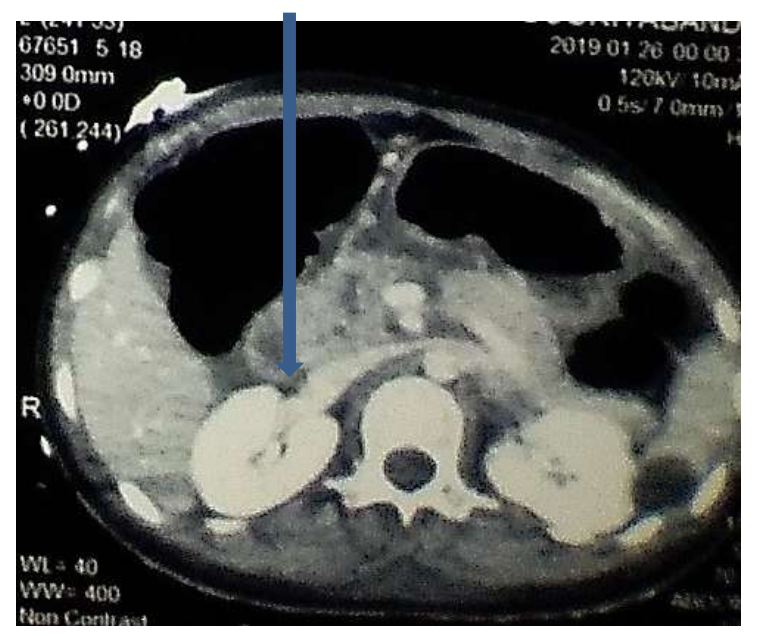

She was managed conservatively as advised by the gastroenterology and the surgical teams. She was hydrated well with intravenous fluids and started on total parenteral nutrition. She was kept nil by mouth. Analgesia was provided with PCA morphine and i.v. paracetamol. She had persistent tachycardia over $120 \mathrm{bpm}$ and spiked fever a few times over the following 4 days. Septic screening was done, and antibiotics were given on the advice of the microbiologist.

Clinical improvement was seen over the next 3 days with decreasing serum amylase levels to 69 $\mathrm{IU} / \mathrm{L}$ and $\mathrm{WBC}$ count to $17 \times 10^{3} / \mu \mathrm{L}$.

On post-operative day 6 a soft diet was started while continuing TPN which was tailed off later. She was comfortable when mobilized. Repeat CT showed improvement of acute pancreatitis and she was discharged on the $10^{\text {th }}$ postoperative day.

\section{Discussion}

Acute pancreatitis following spine surgery has been reported as a rare complication with a low incidence $(7.4 \%) .{ }^{6}$ Although the exact mechanism is still unclear there are well 
recognized risk factors such as direct trauma to pancreas from pedicle screws, use of high speed drilling, re-alignment of the spine, mechanical compression of pancreas due to prone position, low BMI, intraoperative hypotension, decreased splanchnic circulation, massive haemorrhage and long segment of fusion. ${ }^{6,7,8}$

According to the Atlanta criteria, ${ }^{9,10}$ to diagnose acute pancreatitis it requires two of the following three criteria: (a) abdominal pain strongly suggestive of acute pancreatitis, (b) serum amylase and/or lipase level at least 3 times higher than the upper limit of normal level or (c) hallmark imaging findings. This patient had all three features suggestive of acute pancreatitis.

Our patient underwent high-grade correction surgery for higher Cobb's angle and long segments of fusion. She had a low BMI and there was significant intraoperative blood loss of $>40 \%$ of total blood volume. During the intraoperative period, vasopressors or inotropes were not used. The surgery itself was prolonged and done on prone position. She probably would have had hypo perfusion of the pancreas, caused by intraoperative blood loss, together with prolonged prone position which reduces retroperitoneal perfusion, thus leading to pancreatic ischaemia.

Low BMI results in less fat deposition around the pancreas intra-abdominally and in the retroperitoneal region leading to direct compression of the pancreas in prone position. This could cause pancreatic ischaemia and development of acute pancreatitis postoperatively.

The degree of correction or long segment fusion might be an independent risk factor for development of acute pancreatitis. ${ }^{6}$

\section{Conclusion}

Pancreatitis following spinal surgery is an unusual complication with potentially disastrous outcome. Early diagnosis and management plays a key role in preventing severe morbidity and mortality. Acute pancreatitis needs to be considered in patients with post-operative gastrointestinal symptoms and signs. Pancreatic enzymes should be evaluated together with radiological investigations for early diagnosis. Multidisciplinary approach in the fields of general surgery, gastroenterology, radiology and intensive care is recommended for diagnosis and successful management.

\section{References}

1. Ponka JL, Landrum SE, Chaikof L. Acute pancreatitis in the postoperative patient. Arch Surg 1961;83:475-490

https://doi.org/10.1001/archsurg.1961.0130015014 $\underline{9020}$

PMid:13736996

2. White MT, Morgan A, Hopton D. Postoperative pancreatitis. A study of seventy cases. Am J Surg 1970;120:132-137 https://doi.org/10.1016/S0002-9610(70)80100-3

3. Ohri SK, Desai JB, Gaer JA, Roussak JB, Hashemi M, Smith PL, Taylor KM. Intra-abdominal complications after cardiopulmonary bypass. Ann ThoracSurg 1991;52:826-831 https://doi.org/10.1016/0003-4975(91)91219-L

4. Thompson JS, Bragg LE, Hodgson PE, Rikkers LF. Postoperative pancreatitis.SurgGynecolObstet 1988; 167:377-380

5. Drissi M, Madani M, Hatim A et al. Severe acute pancreatitis after surgical treatment of a ruptured abdominal aortic aneurysm. Ann VascSurg 2009;23:785.e5e7

6. Feng $\mathrm{F}$, Tan $\mathrm{H}, \mathrm{Li} \mathrm{X}$ et al. Incidence and risk factors of acute pancreatitis after scoliosis surgery: a prospective study. Spine 2018;43:630-6. https://doi.org/10.1097/BRS.0000000000002389 PMid:29016446

7. Laplaza FJ, Widmann RF, Fealy $\mathrm{S}$ et al. Pancreatitis after surgery in adolescent idiopathic scoliosis: incidence and risk factors. J PediatrOrthop.2002;22:80-3.

https://doi.org/10.1097/01241398-20020100000017

8. Debi U, Kaur R, Prasad KK et al. Pancreatic trauma: a concise review. World J Gastroenterol. 2013;19:9003-11. https://doi.org/10.3748/wjg.v19.i47.9003 PMid:24379625 PMCid:PMC3870553

9. Banks PA, Bollen TL, Dervenis C, et al. Classification of acute pancreatitis-2012: revision of the Atlanta classification and definitions by international consensus. Gut. 2013;62:102-11 https://doi.org/10.1136/gutjnl-2012-302779 PMid:23100216

10. Revised Atlanta Classification. https://pubs.rsna.org/doi/pdf/10.1148/rg.20161500 97 